\title{
The role of ICT in contemporary families
}

\author{
P. Kalibová \\ University of Hradec Kralove, Hradec Králové, Czech Republic
}

\begin{abstract}
Information and communication technologies are a new phenomenon in contemporary society. Today society is often called "learning society", or "society of information and media", we are talking about the digital generation. There are a lot of discussions about the role of information and communication technologies in education and also a lot of vocational researches oriented on this topic. This paper is focused on the role of ICT in families, which is a quite unexplored area. The goal of the paper is to show some results of the research, which was oriented on some changes in communication between generations or the ways of using modern technologies in families. Almost one thousand of young people between 17 and 22 years old have answered the questions in the questionnaire.
\end{abstract}

\section{The role of ICT in current family}

Parents necessarily need to be educated, and gain experience of using the information and communication technologies, so they can support and direct their child in this area [1]. Nowadays, there has been a whole range of options of supporting the awareness of parents about this issue, such as printed or electronic manuals, websites, professional publications, educational courses, etc. [2]

" $86 \%$ of young people that use the internet were given instructions from their parents on how to use it safely, and also $58 \%$ of these users claim that parents have the most significant influence on what they later consider right and wrong while using the internet" [3].

Lenhart et al. [3] also states that $80 \%$ of parents, who have their own profile on social networks, have their children added as a friend, so they can share information and inspect the content their offspring release. $77 \%$ of parents have at some point checked what kind of websites their child visits, and $66 \%$ of parents have searched for available information about their child on the internet. 54\% of parents use software designed to monitor the children's web browsing or a parental lock. Eight out of ten teenagers that are online are connected to social networks.

Parents' approach to the websites that their children visit is far more responsible than it was in previous years. While in the year $200061 \%$ of parents had checked the browse content, in 2011 it was $77 \%$ [3]. The following chart illustrates the extent to which the parents are active in the primary prevention of risky behaviour on the internet, it compares the opinions of parents and children on this issue [3].

It is apparent from the chart that the perception of the discussion about the issue of ICT substantially differs from the points of view of parents, and their children. Whilst children are much more critical of their parents, almost $100 \%$ of parents think that they are instructing their children on the dangers of modern technologies.

However, the parental supervision of their children's behaviour on the internet and other media can be very difficult, and can lead to conflicts and intergenerational gap in the family. Also the young generation's decreasing need of personal communication, and increasing need 


\section{Response to the question: "parents talked with their children about..."}

information that can and can not be published on the Internet

safe use of the Internet and smart phones

how to behave towards other users

childrens'action on the Internet

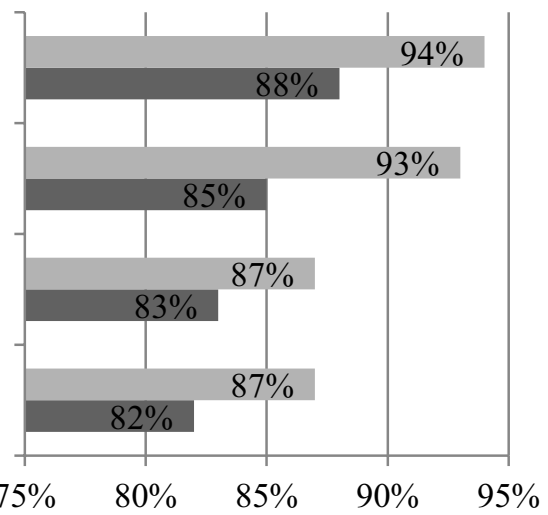

parents

- children

Figure 1. Chart of the responses of children and parents on the subject of joint discussion about ICT.

\section{Parents' dissatisfaction over the media content in 1998 and 2006}

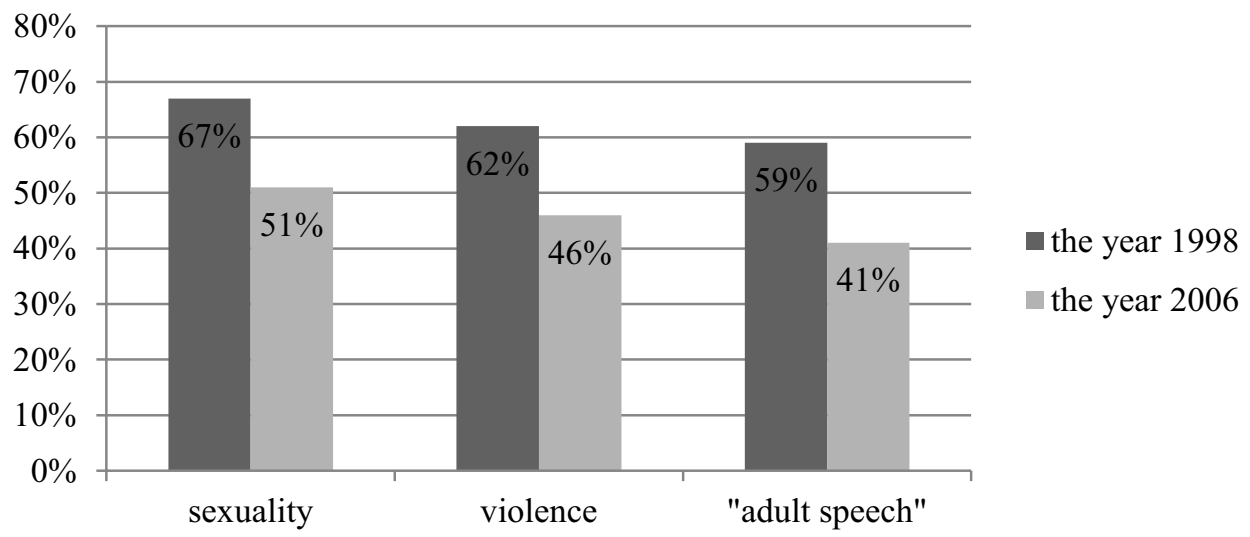

Figure 2. Chart of parental dissatisfaction with the media content in 1998 and 2006 [4].

of communication with their peers via media, can have a negative impact on the relationships in family [5].

Subrahmanyan and Greenfield [5] are confident that if a child uses social networks, it has a negative impact on the relationships with their parents, the conflicts between parents and their child are increasing, and the parental control is decreasing (till it completely disappears).

\section{Research inquiry}

In terms of the issue of the use of information and communication technologies in family a research inquiry was carried out that answers the basic questions arising from this issue. The aim of the research inquiry was to determine the current status of the use of computers in families with an emphasis on the respondents' personal relationships with computers, also within the family they live in, and the extent of their parents' supervision of their work with a computer. For research purposes, an original questionnaire was drawn up, which contains 
Table 1. The order of the statements according to the degree of consent (in accordance with the M number).

\begin{tabular}{|l|l|}
\hline Statement & M \\
\hline 19. My parents pay for my internet connection. & 4.38 \\
\hline 7. I think that I understand the internet better than my parents. & 4.21 \\
\hline 22. I like it when I am home alone at the computer. & 3.98 \\
\hline 21. I would like to be left alone at my computer, and not be cared about. & 3.6 \\
\hline 18. If I got to a risk situation on the internet, I would tell my parents. & 3.55 \\
\hline $\begin{array}{l}\text { 33. My parents trust me that I am not cheating them at the computer, and fulfil their wishes } \\
\text { and bans. }\end{array}$ & 3.55 \\
\hline 1. Every member of my family uses the internet. & 3.31 \\
\hline 28. I think that other members of my family have their own "computer" secrets. & 3.08 \\
\hline 3. My parents know what I do on the computer. & 2.84 \\
\hline 4. My parents know what websites I visit. & 2.7 \\
\hline 15. I have at least one parent in my friends on a social network. & 2.63 \\
\hline 30. In other families, the parents are less severe with their children regarding computer use. & 2.46 \\
\hline 8. Our computer is placed so that everyone can see what I am doing at the moment. & 2.35 \\
\hline 5. I say to my parents that I am studying by means of the internet, but it is not truth. & 2.31 \\
\hline 23. I hide what I do at the computer at home. & 2.25 \\
\hline 2. We have one computer in our family that is used by all of us. & 2.14 \\
\hline 6. My parents and I share the internet. & 2.03 \\
\hline 32. My parents try to keep me away from the computer. & 1.92 \\
\hline 12. My parents buy me new devices that allow me to access the internet. & 1.85 \\
\hline 16. My parents talk to me about certain dangers of the internet. & 1.81 \\
\hline 31. My parents forbid me some things on the computer just to demonstrate their power. & 1.76 \\
\hline 29. I think that my parents watch me at my computer too much. & 1.72 \\
\hline 20. At home, I argue over the use of the computer with other members of my family. & 1.69 \\
\hline 10. My parents regulate the frequency and the time for which I am allowed to use the internet. & 1.55 \\
\hline $\begin{array}{l}\text { 9. My parents use such computer settings that allows them to regulate } \\
\text { what and when I can do at the computer. }\end{array}$ & 1.51 \\
\hline 14. My parents check my activity on social networks. & 1.33 \\
\hline
\end{tabular}

33 statements that are directed at different attitudes of the respondents to computer as a person, as well as within the family they live in. Each statement is accompanied by the attitude scale of Likert's type with a range from a strong disagreement $=1$ point, to a strong agreement $=5$ points. The research set $(\mathrm{N}=896)$ consisted of 573 men and 323 women aged from 17 to 22 years; age $\mathrm{M}=17.07, \mathrm{SD}=1.59$.

The table below shows individual statements of the questionnaire according to the degree of the respondents' consents.

The research inquiry shows that parents are the ones who pay for their children's internet connection, and that applies also to the age when the young generation is already able to make their own money by doing part-time jobs. Moreover, the research inquiry confirmed that secondary school youths own more than one device that allows them to access the internet. Young people believe that they understand the modern technology better than their parents. The secondary school students prefer privacy while using the computer, and they would appreciate if their parents would not disturb them during that time. Our research also showed, that if the respondent got into an endangered or threatening situation on the internet, they would tell their parents about it. However, on the other hand, the research clearly shows that parents are not too involved in the primary prevention of risk phenomena associated with media. The respondents least agree with parents, monitoring their children's activity on the social networks. Parents do not even use the computer settings, which can regulate the internet content their child is viewing, or the allowed time duration of being online. 
The older the respondents are, the less they experience the parental control and supervision over their computer use. The decreasing parental supervision might be a result of either the parents having an experience with their child, who did not have any problems with using the computer, or the parents having fewer and fewer chances to control in detail, mainly because the adolescent is giving them fewer and fewer daily opportunities to do so.

The most the respondents perceive the controlling by parents with elementary education, the least by parents - university graduates. A parent with elementary education can have the impression that their child, sitting at the computer, is "running away" towards the world they are not always fully acquaint with, and thus they intensify the control. A university graduate parent quite automatically assumes that their child has the same attitudes, which they themselves have, and so they give their child a bigger freedom in a number of things. The bigger the parents' income, the less they control the respondent in their work with computer.

\section{Summary}

The results of the research show that primary prevention of risk behaviour in the connection of ICT is still not at a satisfactory level. The parents should have more information about this very topical issue. The communication in families is changing - the young generation prefers communication via social networks and it deepens the generation gap in families. The results show that the issue of ICT is very current and it is important to be focused on this topic also in future from many views.

\section{References}

[1] O. Stevenson, Journal of Computer Assisted Learning, From Public Policy to Family Practices: Researching the Everyday Realities of Families' Technology Use at Home, 27, 336-346 (2011).

[2] L. Hulanová, Internetová kriminalita páchaná na dětech. Psychologie internetové oběti, pachatele a kriminality, 217 (2012).

[3] A. Lenhart et al., Pew Research Center's Internet and American Life Project, Teens, Kindness and Cruelty on Social Network Sites. How american teens navigate the new world of "digital citizenship", 86 (2011).

[4] V. Rideaut, The Henry J. Kaiser Family Foundation, Parents, Children and Media. A Kaiser Family Foundation Survey, 38 (2007).

[5] K. Subrahmanyan, P. Greenfield, The Future of Children, Online Communication and Adolescent Relationships, 18, 1 (2008). 